\title{
ALTERNATIVE SOLAR INDICES
}

by

Loren J. Lantz

Solar Environmental Engineering Company, Inc.

2524 E. Vine Drive

Fort Collins, Colorado 80524

\section{MASTER}

$$
\text { July } 7,1980
$$

This work was prepared under Contract No. DE-AC02-78ET-20090

$$
\text { for }
$$

Training Information and Education Branch Conservation and Solar Energy

U. S. Department of Energy

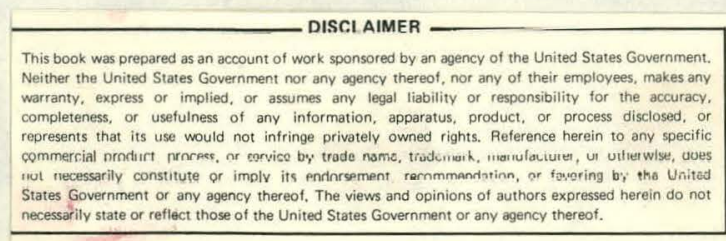




\section{DISCLAIMER}

This report was prepared as an account of work sponsored by an agency of the United States Government. Neither the United States Government nor any agency Thereof, nor any of their employees, makes any warranty, express or implied, or assumes any legal liability or responsibility for the accuracy, completeness, or usefulness of any information, apparatus, product, or process disclosed, or represents that its use would not infringe privately owned rights. Reference herein to any specific commercial product, process, or service by trade name, trademark, manufacturer, or otherwise does not necessarily constitute or imply its endorsement, recommendation, or favoring by the United States Government or any agency thereof. The views and opinions of authors expressed herein do not necessarily state or reflect those of the United States Government or any agency thereof. 


\section{DISCLAIMER}

Portions of this document may be illegible in electronic image products. Images are produced from the best available original document. 
This report was prepared as an account of work sponsored by the United States Government. Neither the United States nor the United States Department of Energy, nor any of their employees, nor any of their contractors, subcontractors, or their employees, makes any warranty, express or implied, or assumes any legal liability or responsibility for the accuracy, completeness, or usefulness of any information, apparatus, product or process disclosed or represents that its use would not infringe privately owned rights. 


\section{ALTERNATIVE SOLAR INDICES}

\section{Abstract}

The current Solar Index project is becoming quite well defined and is running smoothly. The time has come to think about possible alternative Solar Indices which could either be a perturbation from the currently defined Solar Index or possible indices : based on current technologies for other media markets. This paper gives an overview of the current project, including the logic that was utilized in defining its current structure and then alternative indices and definitions are presented and finally, recommendations are made for adopting alternative indices.

\section{Introduction}

In 1978, an interoffice committee was formed, headed by the Training and Education Branch of the U. S. Department of Energy for the purpose of investigating and defining a Solar Index. The objective of the Solar Index was to introduce the concept of solar energy usability, and not availability, and to inform the general public that solar energy technologies could be utilized to provide energy and to save money. Various definitions and guidel ines were adopted. The guidelines will be given later in this paper. The committee wanted to reach the buying populus and to put the idea in . their heads that solar energy could indeed do something for them. The resulting Index was not intended to service the already prevalent solar advocates. The committee wanted to penetrate the majority of the buying class that was not fully aware of solar energy availability. In an effort to fulfill this objective, an index was sought that was patterned after an existing well defined and commercially viable solar technology. The solar servjce hot water system fit this definition closer than any other 
solar technology at the current time. Solar service hot water systems were being widely sold throughout the country. The technology was basically well understood, it was simple in nature and it was something that could be utilized in the country irregardless of location and irregardless of time of year. Consequently, a Solar Index was quite easily defined based on a generic service hot water system.

Ten cities were selected to receive the initial Solar Indices. They were large metropolitan areas across the country. Also, a simple service hot water system was defined for each location so as to be representative of what was currently being installed in each particular location at the time. It was decided to size the solar system that would be used to create the individual Solar Indices through computer models so that they would give an annual load fraction of 70 to $75 \%$. This yielded collector areas from. $40 \mathrm{ft}^{2}$ to over $90 \mathrm{ft}^{2}$. Also, the solar system had regional variations. These could be singie glazed collectors in the south, double glazed collectors in the north and freeze protection mechanism in the north and none in the south. Next, a computer model was adapted so that individual daily performance indices could be extracted on a timely basis so that they could be delivered to the media and individual cities immediately after local sundown. The SOLCOST computer program was adopted as the modeling tool and computer models were developed so as to model these particular solar systems for each location and each day's weather. The load on the system was assumed to be 80 gallons in all locations.

Initially, the weather information that was used by the computer model was obtained by calling local weather service offices after sundown to get percent of sunshine and temperature information. The project steadily 
grew to where it is at the current time, which includes over 175 cities (see Fig. 1) and which will expand to over 200 by the end of calendar year 1980. It became obvious very quickly that these phone calls could not be utilized in all locations, nor was it desirable to do so because of the labor requirements. Considering this, alternatives were sought. In 1980, existing weather wire outlets were tapped in an effort to automate the acquisition of weather information and also in an effort to el iminate the personal contact requirement (i.e., daily phone calls).

The Federal Aviation Administration produces a weather wire information outlet, which is an accumulation of many existing National Oceanographic and Atmospheric Administration and National Weather Service wires. This information is broadcast hourly over existing networks throughout the United States. The information is automatically accessed by computer and stored. Then specialized software and various computing systems are utilized to transform the observed weather information into parameters that could be easily be transformed into individual Solar Indices. This whole project has been well automated and is currently running smoothly.

A scheme has recently been implemented so that the Indices can be delivered-in mid-afternoon for each time zone so that it can be included on the early evening news. The Indices at the current time are automatically delivered to United Press International for distribution over their press wires and broadcast wires. This is done again by computer so as to make the whole process as timely as possible.

The current Index definition does one thing above all else, and that is to promote the utilization of solar for heating hot water, which is something that every American household can utilize. However, there are other solar technologies which could benefit just as much, or even possibly more. A 


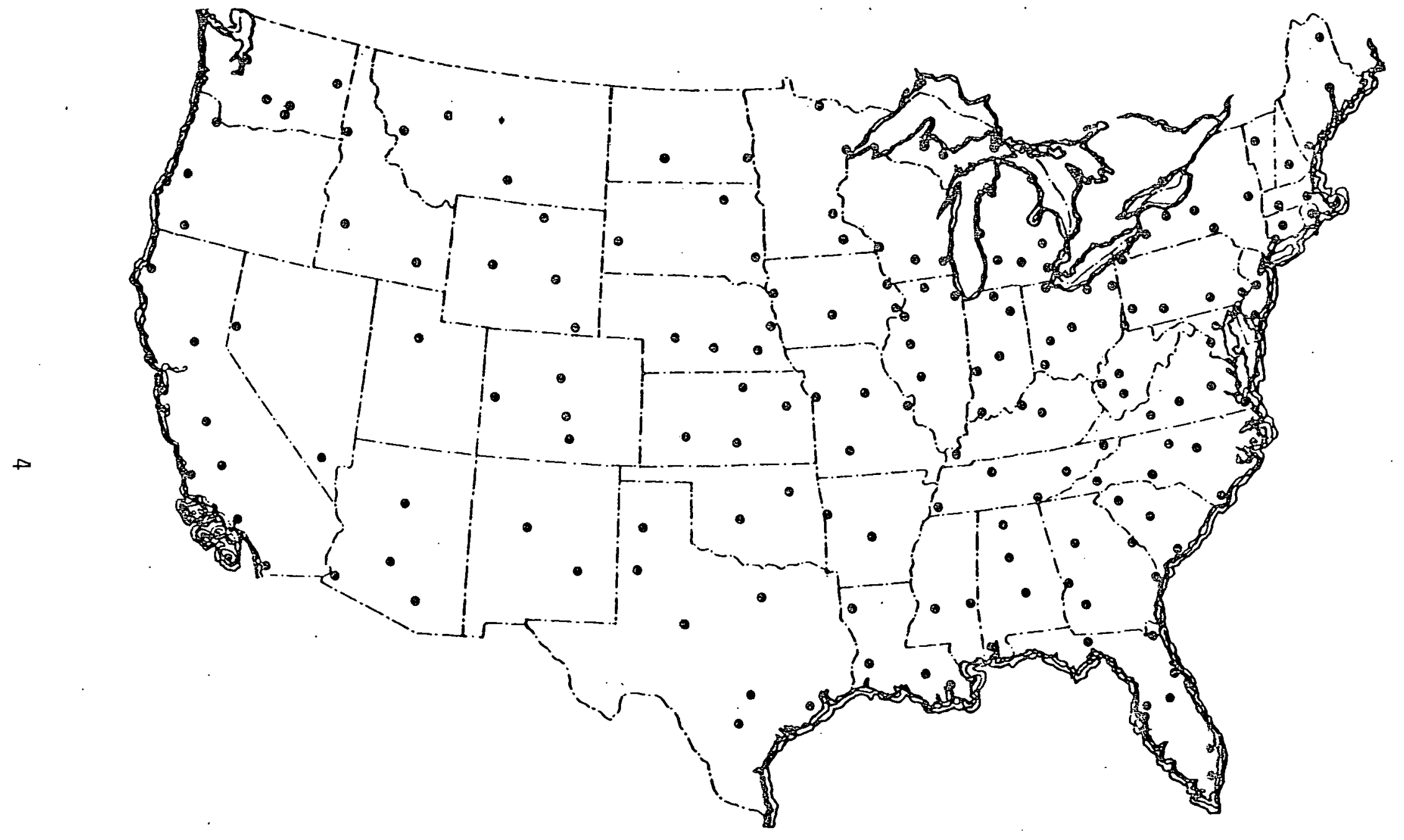

Figure 1. Solar Index Locations (June, 1980) 


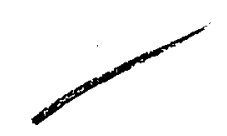

problem arises, however, if other Solar Indices were developed which seemed similar in concept which were patterned after other solar system technologies. The end result would probably be confusion to the individual. There would be a myriad of numbers floating around and it would especially be true if they were all delivered in a similar fashion. The medila has also made it quite plain that they are only interested in disseminating one number each day. However, within a few years, the current Solar Index would probably become "old hat" and if the project is to continue, a new Solar Index will need to be defined and this would be the time to introduce a Solar. Index patterned after other types of technologies. There is also the possibility of releasing Solar Indices for other types of media outlets.

\section{Current Project Status}

The solar Index is a number between 0 and 200 which represents the percentage of energy made available by a solar system that is used to heat an 80-galion per day semice hot water load for a given geographic Zocation and given day. Fox example, if the Solar Index is 70 for a given day, it means that a solar service hot water system could provide approximately 70 percent of the heat needed to boost 80 gallons from ground water temperature to $120^{\circ} \mathrm{F}$. The Solar Index is much like the pollen count, wind chill factor, and air quality index, in that it can provide more useful information than can be provided by observations such as ambient temperature or carbon monoxide concentrations.

The objective of the Solar Index ${ }^{*}$ effort is to increase public awareness. Approximately two years ago it was decided within a U. U. interoffice committee that an index, general in nature, would increase public awareness of

+ Additional information, general in nature, can be obtained by writing to Solar Index, Conservation and Solar Energy, U.S. Department of Energy, Forresta? Building, Washington, D.C. 20585. 
solar energy. Several indices were investigated and it was decided that the Index should provide an indication of what the sun can do for the individual rather that to simply state how much solar radiation is available. That is why the current definition of the Service Hot Water Solar Index has been adopted--because it does give an indication of what the sun is capable of doing for the individual. The solar service hot water system was decided upon as a base because it appears to be one of the most commercially viable and is the most easily defined and most frequently installed solar system in the country at the present time. Also, the average hot water usage for a service hot water heating system is fairly constant throughout the country.

In the beginning of the project, initiation of the Solar Index for any given city required that the media in that city request the Solar Index. At the present time, cities which are prime market areas are being added to the list whether or not the media have shown interest. Media interest, however, will increase the motivation for inclusion. After deciding to possibly include a site in the effort, the SOLCOST Service Center ${ }^{\dagger}$ selects the appropriate solar system type and determines the availability of weather information. Weather service information is essential.

Once it has been ascertained thal dill mecessary information is available, the computer files required for generation of the daily Index are created. This is accomplished with SOLCOST, which is a computer program used to analyze prospective solar energy systems of various types on the basis of economics and thermal performance. It is basically a design tool which

T Technical responsibility for the Solar Index is provided by the SOLCOST Service Center, 2524 E. Vine Drive, Fort Collins, Colorado 80524. Specific techical questions not addresscd by this paper should be addressed to Loren J. Lantz. at. the above address. 
provides the user with the necessary information to facilitate decisions regarding a solar energy system. As pertaining to the Index, SOLCOST is used to size the system and then produce a data base of performance values based on historical weather data. The inputs to the program are: location, orientation, size of specific components, the load, and the location's weather history.

A simplified data base is created with the two inputs being average ambient temperature and percent sunshine with the output being the Solar Index. This may be accomplished either by tabular or graphical means. Both methods of analysis are easily implemented.

The Solar Index process is two-phased. The first phase is setting up and the second phase is execution. Involved in setting up is the decision to include a location. Then if weather service information is available, the necessary computer files are created for execution of the Index procedure on a daily basis. Execution of the Index on a daily basis requires. utilization of computer files; which has already been defined in the setup phase.

As the Solar Index project currently stands, the Department of Energy, Conservation and Solar Energy Applications, provides direction for the overali project. There are two prime contractors who provide support to the Department of Eneryy. They are 1) SOLCOST Service Center, :2624 E. Vine Drive, Fort Collins, Colorado 80524; and 2) National Solar Heating and Cooling Information Center, 20th and Race Streets, Philadelphia, Pennsylvania 19103.

The SOLCOST Service Center provides technical direction for the project. Its personnel are responsible for determining availability of weather information and setting up computer files for execution of the Solar Index on a daily basis. They are also responsible for delivering the Solar Index in an automatic fashion to the news wire services, which is done at the present time by direct computer ties. 
The National Solar Heating and Cooling Information Center in Philadelphia is responsible for delivering the Solar Index to interested parties who do not subscribe to the news wire services. They are delivered each evening by telephone. Individuals at the SOLCOST Service Center phone the Index number to the National Solar Heating and Cooling Information Center each evening for dissemination to those people who wish to receive the number by phone. They are also responsible for tabulating monthly summaries, keeping records, and dissemination of media information to interested parties.

There are two other agencies which are also very important. They are the United Press International, which at the current time is disseminating the Solar Index daily through its wire services, and a computer service agency located in Massachusetts, which collects the weather data each hour from the prime weather wires, including the wires generated by National Weather Service, National Oceanographic and Atmospheric Administration, and the Federal Aviation Administration. The latter is the one that is used primarily in the generation of the Index. More will be given later about how this weather data is transformed into a Solar Index for a given city.

At the present time, most large metropolitan areas (Fig. 1) are being serviced by the Solar Index effort. The Department of Energy is constantly striving to inform the media of this new service, especially in the prime solar commercial market areas of the country.

The current effort has been thoroughly explained so that the reader would become familiar with the logic used in defining the current project. Now, 'spectfically the generalized guidelines, as adopted through the conception of this project, are given. 
1. The system used as a basis for the Index must be commercially viable throughout the country.

2. The system must have an easily described configuration so that the public can understand its function and operation.

3. The thermal load seen by the solar system should be similar for most locations in the country.

4. The system's performance must be easily modeled so that individual indices can be quickly and accurately determined.

5: The solar system size must be easily and definably scaled so that the individual indices are comparable throughout the country.

These guidelines have served this project well and there is no reason that they should.not serve in any future projects as well, even with possible future modification.

\section{Other Solar Technologies for Defining Indices}

There are several currently definable solar technologies that could be referenced in defining a Solar Index patterned in the way the current one is defined; that is, the Solar Index is a daily performance value of some type for a particular type of solar system. Some of the technologies are as follows:

1. space: heating, ;both active or passive,

2. space cooling, also both active or passive,

3. industrial process heat,

4. photovoltaics for generation of electricity for household use or industrial use,

5. collection of heat for specific purposes such as possibly crop drying or for work such as pumping water.

All of these technologies could benefit from a Solar Index that was defined in such a way so that it would improve the public's awareness to the fact that the 
sun can provide some service. Indices should be developed for those technologies that are the most commercially viable and proven. For purposes of defining an index, most of those listed would be difficult at best. For example, space heating systems, either active or passive, do not have a consistent load throughout the year, so a space heating Solar Index has very little meaning in the summer. Likewise a space cooling Solar Index would have little meaning in the wintertime. This would be true whether it was active or passive. Industrial process heat applications have little meaning to the populus at large. The audience that would be interested in that technology is smalT. The technology that is probably the most amenable to developing a Solar Index patterned after the current project would be utilization of photovoltaics for generation of electricity. Virtually all households in the country at the current time utilize electricity throughout the year. A photovoltaic Solar Index could be defined to where it would have meaning throughout the year and throughout the country. It need not be based on a percentage, as the current Solar Index is. It could simply be the number of kilowatt-hours displaced by the solar system and the representative system could be sized in such a way to where the total amount of displaced energy would be the same for most locations in the country. The catch here, however, is that this particular technology is not currently available at the current time. It will probably be a few years before photovoltaic systems for displacing electrical energy are widespread and commercially availabie. :All that is left are particular application usage of solar energy such as utilization of solar energy for agricultural use.

If deviation from the basic guidelines were allowed, possibly Solar Indices could be developed for selected media outlets. These could include special interest publication; i.e. Sunday supplements for major newspapers, and indices could be created which would only be released through certain regions of the 
country and certain periods of the year. For example, a performance index could be generated for passive direct gain.solar s.ystem for some standardized application and weekly indices could be released which were intended solely to be published in small boxes in Sunday papers or supplements to Sunday papers in the predominantly colder regions of the country where passive space heating would be most applicable.

The current software used to collect weather information.could be utilized and new modeling techniques would have to be developed or current ones adapted so that performance indices could be generated quickly so theat the information could be delivered to the media on a timely basis. The indices need not be called indices and can be generated for one time only. For example, special feature articles for special interest publications, such as define a system for a specific application such as a car wash, then determine what the performance would have been for that particular system for a specific month and then write a feature article to be printed in a magazine which would reach the audience who could most benefit from such an article. However, every effort must be made so as to prevent any confusion. As long as the current project is in operation, there can only be one Solar Index released. All other indices will have to adopt some other ndine and specifically not use the word "Index". A large number of possibilities exist.

The current methodology creates and collects a wealth of information that could be. used for the generation of many different types of indices and performance factors that could be used for public information. This would aid the indices and the cause for conserving energy and do enveryone a service. However, the media will need to be contacted as well as the individuals who are 
trying to market specific types of solar systems which could find benefit in being armed with daily performance factors for specific types of systems. Marketeers may be more capable of placing solar systems of various types into the marketplace. Probably the best indication of what type of Solar Index would be most appropriate for furthering the industry as a whole is to determine what types of systems other than service hot water are producing the greatest number of sales at the current time and also which ones are expected to produce the greatest number of sales in the future, both in number and total dollar amount.

\section{Recommendations}

Two basic recommendations come to mind in reviewing the work that went into the preparation of this paper. One is that research should be performed so as to define an index that would be later implemented that would replace the current Solar Index. The current definition will sooner or later become of little use and new bells and whistles will need to be added so as to revive public awareness of a Solar Index. The easiest way to do this would be to change the basic system that is used to create the performance index which is turned into a Solar Index. The most logical one would possibly be a photovoltaic system. That is not to mean it is the only possibility; it is the only one that satisfies the current established guidelines. The second recommendation would be to contact the Regional Energy Centers and find out what type of special interest publications for those specific regions would best be serviced by the generation of periodic indices for specific types of solar systems. The Regional Energy Center's are probably best aware of what type of articles would be most appropriate for their regions and for what types of solar systems. Mechanics are currently in effect for generation of performance-indices in a timely fashion once it has been decided what the 
reference solar system is to be. All sorts of possibilities exist and a great deal of money and labor has been expended to create the mechanisms for timely collection of weather information for generation of the currently defined Solar Index. Every avenue should be thoroughly investigated so as to give this information the widest possible dissemination so that it can provide the greatest use to the public at large. 